\title{
High-Resolution Mapping of Anthropogenic Heat in China from 1992 to 2010
}

\author{
Wangming Yang ${ }^{1}$, Bing Chen ${ }^{2}$ and Xuefeng Cui ${ }^{1, *}$
}

1 State Key Laboratory of Earth Surface Processes and Resource Ecology, College of Global Change and Earth System Science, Beijing Normal University, Beijing 100875, China;

E-Mail: yangwm2012@gmail.com

2 State Key Laboratory of Remote Sensing Science, Institute of Remote Sensing and Digital Earth, Chinese Academy of Sciences, Beijing 100101, China; E-Mail: chenbing@mail.iap.ac.cn

* Author to whom correspondence should be addressed; E-Mail: xuefeng.cui@bnu.edu.cn; Tel.: +86-10-5880-2701; Fax: +86-10-5880-2165.

Received: 11 February 2014; in revised form: 28 March 2014 / Accepted: 2 April 2014 /

Published: 14 April 2014

\begin{abstract}
Anthropogenic heat generated by human activity contributes to urban and regional climate warming. Due to the resolution and accuracy of existing anthropogenic heat data, it is difficult to analyze and simulate the corresponding effects. This study exploited a new method to estimate high spatial and temporal resolutions of anthropogenic heat based on long-term data of energy consumption and the US Air Force Defense Meteorological Satellite Program-Operational Linescan System (DMSP-OLS) data from 1992 to 2010 across China. Our results showed that, throughout the entire study period, there are apparent increasing trends in anthropogenic heat in three major metropoli, i.e., the Beijing-Tianjin region, the Yangzi River delta and the Pearl River delta. The annual mean anthropogenic heat fluxes for Beijing, Shanghai and Guangzhou in 2010 were $17 \mathrm{Wm}^{-2}, 19$ and $7.8 \mathrm{Wm}^{-2}$, respectively. Comparisons with previous studies indicate that DMSP-OLS data could provide a better spatial proxy for estimating anthropogenic heat than population density and our analysis shows better performance at large scales for estimation of anthropogenic heat.
\end{abstract}

Keywords: anthropogenic heat; urban heat island; DMSP-OLS; major metropolis 


\section{Introduction}

Anthropogenic heat is wasted heat that is released into the atmosphere in sensible and latent forms [1]. It is released mainly through space heating and cooling, running appliances, transportation, industrial processes, and human metabolism [2-5]. Nearly 70\% of energy is consumed within cities that occupy only $2 \%$ of the Earth's surface area [6]. Therefore, the magnitude of the anthropogenic heat flux (AHF) in urban areas is much larger than that in rural areas. AHF has high spatial and temporal variations which are sensitive to climate zone, population density, economic development, season, time of day, and urban form or function [7-9]. In general, it is larger in winter than in summer, in downtown than in suburbs, in cold climates than in warm climates, in developed areas than in developing areas, in big cities than in small cities. AHF has been suggested as an important contributor for local urban warming [10], annual mean warming across western European [11], and even global surface warming through disruption of atmospheric circulation patterns [12].

AHF can be calculated using either observation or inventory approaches. Observations include surface energy budget measurements [13-15] and in situ eddy covariance observations [16]. Currently, inventory approaches (bottom-up or top-down) are more widely used to estimate AHF from global scale to single city $[8,17]$. The top-down approach is mapping energy consumption from coarse spatial and temporal resolutions to higher spatial and temporal grids $[3,9,18]$. While the bottom-up calculates detailed statistics of the sub-system, i.e., time and volume of traffic, building height and population density of the entire studied urban area [19]. The first global AHF data was released in 2009 (referred as Flanner study hereafter), and used the top-down inventory method to apportion non-renewable energy consumption in a $2.5-\mathrm{min}$ spatial resolution (about $4-5 \mathrm{~km}$ at the equator) mainly based on global map of population density [20]. Flanner study shows unreliable information for some regions such as China, as spatial population density is not a good proxy for economic development or energy consumption in China [21]. The nighttime light data from the US Air Force Defense Meteorological Satellite Program-Operational Linescan System (DMSP-OLS) has been found to be highly correlated with AHF at the provincial level $\left(R^{2}=0.977\right)[22]$ and hence it provides a timely and inexpensive tool to monitor human settlements, GDP, energy consumption, carbon emissions, and spatial population density [23-25]. This encouraged us to produce AHF in China based on the method of Flanner's study [20]. but replacing population density with nighttime light data.

\section{Data and Methods}

\subsection{Multi-Temporal Dataset of DMSP-OLS}

The DMSP-OLS dataset was acquired from NOAA's National Geophysical Data Center[26]. The dataset provides cloud-free composites of DMSP-OLS smooth resolution data from 1992 to 2010 [23]. The dataset for stable average nighttime lights are used in this paper, which are given on 30 arc second grids that span -180 to 180 degrees longitude and -65 to 75 degrees latitude. These data (range from 1 to 63) contain the lights from cities, towns, and other sites with persistent lighting, including gas flares. Ephemeral events, such as fires, have been discarded. Areas with zero cloud-free observations were represented by the value 255 [27]. 


\subsection{Statistical Data}

National primary energy consumption data, including coal, petroleum and natural gas, in China from 1980 to 2012 were provided by the U.S. Energy Information Administration (EIA, available from) [28]. In this paper, we only consider non-renewable energy as this is currently the major resource. Renewable energy makes up only about 5\% of energy consumption in China currently, so it is excluded in this study but should be included in future studies as the renewable energy fraction is increasing rapidly. Some primary energy is used to produce secondary energy (for example electricity) in rural areas which is then finally consumed in urban areas. However, it is difficult to calculate the production efficiency and track down the energy transfer. Energy consumption for some specific cities can be downloaded from database of yearly statistics [29]. The urban areas of some cities were provided by the urban statistical yearbook in China [30].

\subsection{Methods for Calculating AHF}

As shown in Figure 1, we used four steps to calculate AHF:

(1) Since larger DMSP-OLS digital number (DN) represents more active economic activities, areas where $\mathrm{DN} \geq 12$ were classed as urban areas while the remainder are classed as rural regions.

(2) We divide energy consumption (petroleum, coal and natural gas) into two parts: energy used in urban areas and in rural areas. We use the 2009 consumption ratio from IEA ( $87 \%$ coal, $77 \%$ oil, and $81 \%$ gas for urban energy consumption). This ratio may change annually, but should not change dramatically during the study period.

(3) There exists a strong exponential relationship between urban area and energy consumption $\left(R^{2}=0.9\right)$ from the available statistical data (Figure 2). Based on this relationship, energy consumption in the urban area obtained from step (2) is exploited in the urban map obtained in step (1). In China, most large factories or refineries are located in urban areas. Therefore, the energy consumed in urban area not only include the energy consumption for domestic use but also industrial usage. Human metabolism makes up a small share of the total heat released by human activies, and we exclude it here. We note that statistical errors in urban energy consumption are a function of urban area and energy consumption. In order to alleviate their effects, we can allocate total urban energy into patches based on percent-normalized urban energy from Figure 2.

(4) Finally, AHF was calculated using energy data obtained for each urban patch in step (3) according to the percent-normalized DMSP-OLS data in every urban patch and rural region. As data of energy consumption allocated to each grid cell are total energy consumption for corresponding location, the sum consumption is converted to heat flux in each grid $\left(\mathrm{Wm}^{-2}\right)$ by dividing by elapsed time. 
Figure 1. Diagram of estimation for AHF.



Figure 2. Exponential relationship between urban area and energy consumption by city scale (data of urban areas and energy consumption are provided by NBSC, which is used to fit energy consumption to urban area).



\section{Results}

\subsection{AHF Temporal and Spatial Patterns}

Energy consumption from 1992 to 2010 increased greatly in China. Total energy consumption in China rose by nearly a factor of 3.42 from 1992 to 2010, and energy consumption in China exceeded the energy consumption in the United States in 2008 (Figure 3). China is projected to contribute the largest share of global energy use in the near future because the energy demand is expected to rise by $60 \%$ in 2035 [31]. Non-renewable resources have always contributed the largest share of total energy 
resources. Compared with clear trends of energy consumption in China during this period, there are no pronounced increasing trends in the United States. Moreover, the difference in average energy consumption between both countries during this period was 47.1 quadrillion Btu.

Figure 3. Temporal trends of energy consumption from 1980 to 2010 in China (NR: non-renewable resources, data of energy consumption are provided by EIA. This figure shows temporal trends and differences of energy consumption in America and China from 1992 to 2010).

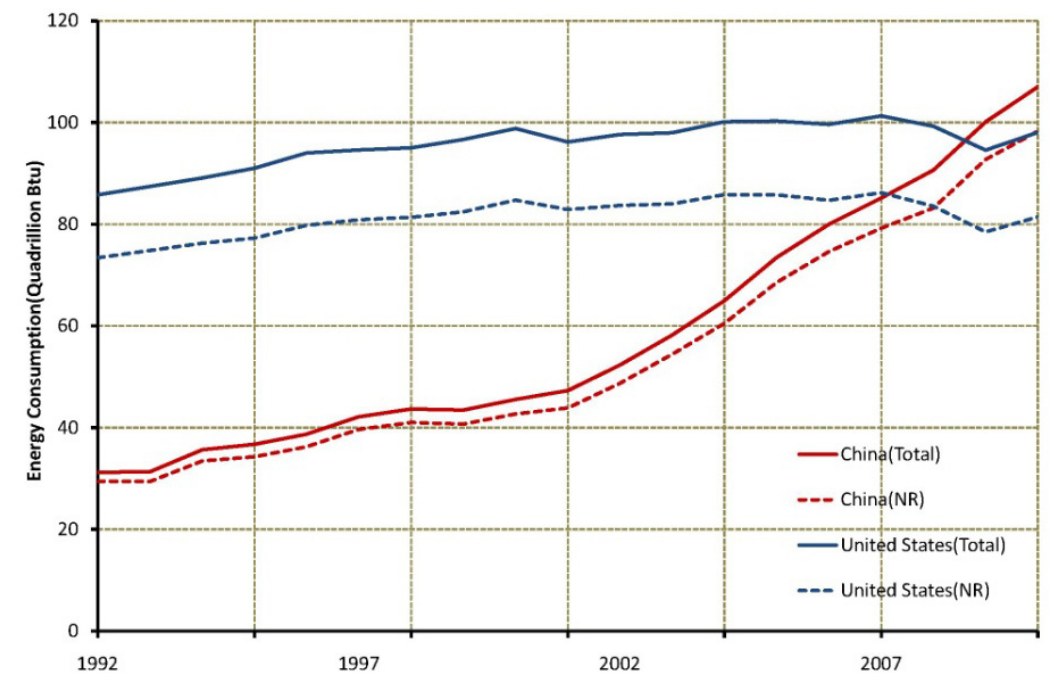

Figure 4 shows that spatial correlation between AHF distribution and economically developed regions is very close since anthropogenic heat is emitted during the energy consumption process. High AHF is concentrated in megacities, e.g., Beijing, Shanghai and Guangzhou; furthermore, the spatial extent greatly expanded during the studied period. Most of anthropogenic heat concentrated on economical developed regions, while less distributed in developing regions.

AHF in China changed greatly from 1992 to 2010. The increasing trend in anthropogenic heat was focused on three major metropolis: the Beijing-Tianjin region, the Yangzi River delta and the Pearl River delta. The Beijing-Tianjin and the Yangzi River delta had the largest changes during the studied period (Figure 4). The cities of Beijing, Shanghai and Guangzhou had the largest single-city AHF change in the three mega-metropolis. The annual mean AHF in Beijing, Shanghai and Guangzhou were 17, 19 and $7.8 \mathrm{Wm}^{-2}$, respectively, in 2010. However, these values were only 9.0, 7.9 and $6.19 \mathrm{Wm}^{-2}$, respectively, in 1992. The AHF in Shanghai city in 2010 was 2.4 times its size in 1992. On the larger scale, the AHF across China changed obviously between 1992-2000 and 2000-2010; the annual mean AHF for China in 1992, 2000, and 2010 was $0.10,0.14$, and $0.34 \mathrm{Wm}^{-2}$, respectively. Large changes were found during the latter half of the studied period; the AHF difference for China from 2000 to 2010 was $0.2 \mathrm{Wm}^{-2}$. The increase in anthropogenic heat in China was primarily due to acceleration of economic growth. 
Figure 4. Spatial patterns of AHF and spatial differences of distributions from 1992 to 2010 (units: $\mathrm{Wm}^{-2}$ ).
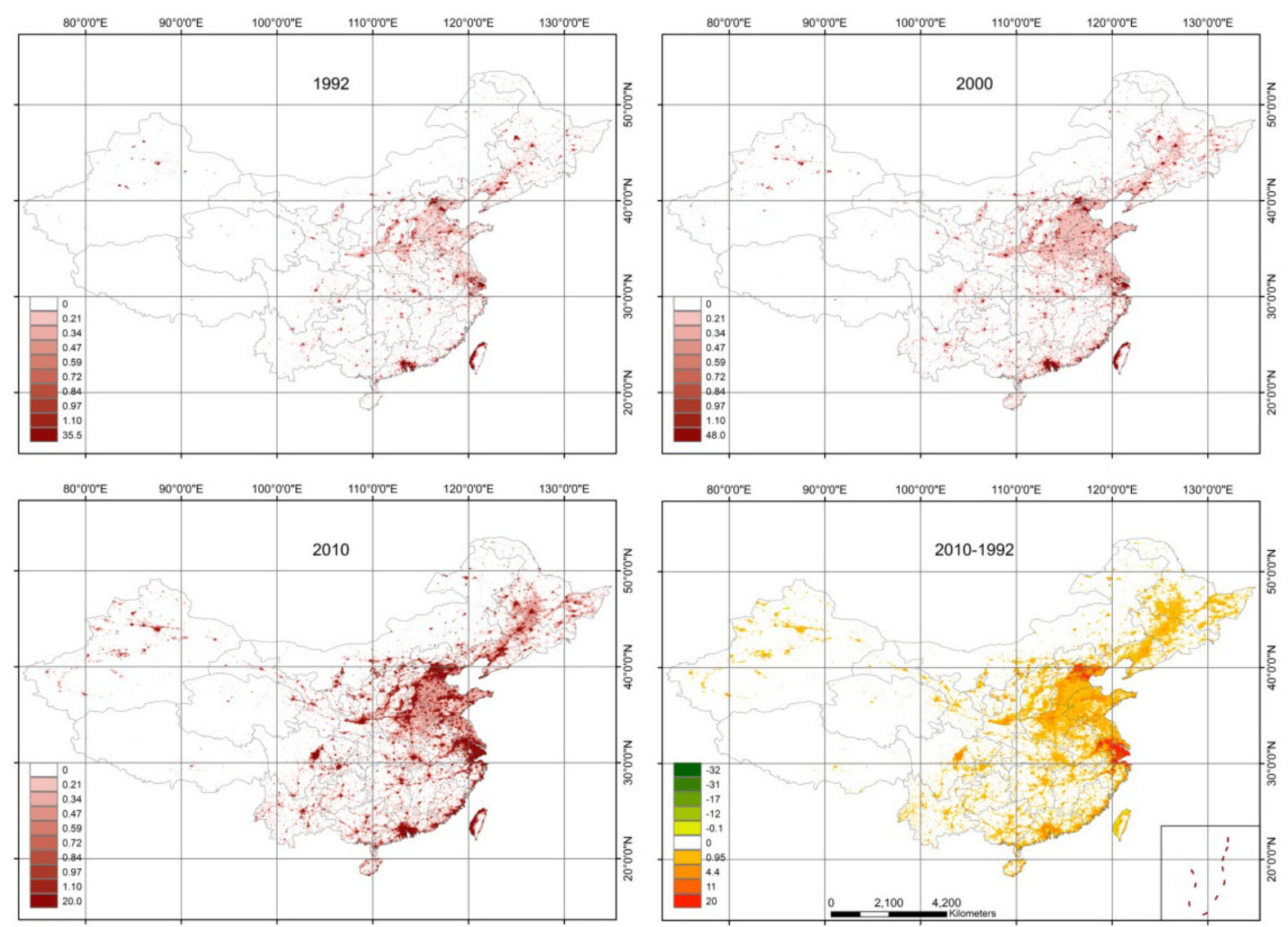

\subsection{Validation}

It is very difficult to evaluate AHF with in situ measurements because identifying whether the sensible or latent heat was emitted from human activity or background conditions is very challenging [32]. Therefore, our data must be validated with other estimated results [33]. This study exploited AHF spatial distributions across China [20], annual average province-level AHF [18,22] and city-scale AHF $[9,19]$ to assess the data.

\subsubsection{Comparison of Data for China}

We compare our data with global AHF data [20] (named Flanner' data), which are estimated by allocating energy consumption by spatial population density. As there are different spatial resolutions for Flanner's data and our data, we must resample these data to uniform resolution $(2.5 \times 2.5 \mathrm{~min})$ to compare them. Figure 5 shows that the AHF spatial discrepancies between Flanner's data and our data are obvious. In urban regions, our data are larger than Flanner's results, and the largest anthropogenic heat release occurred in mega-cities, such as Shanghai and Beijing. In rural regions, our data are generally small compared with Flanner's results. In some western and northwest regions in China, the AHF in Flanner's data are non-zero. However, these regions, such as desert and mountain regions do not consume energy and should have no AHF. 
The fact that our data are larger in urban than rural areas is a result of non-renewable energy resources that were allocated to rural regions in Flanner's analysis and are larger than the actual rural energy consumption. Moreover, accuracy of the spatial population density proxy could result in errors. The annual average AHF estimated by Flanner used yearly energy consumption allocated into spatial population density distributions [20]. AHF data quality depends on the spatial proxy. Spatial population density data were calculated using areas and populations in administration units, resulting in no pronounced statistical spatial change between administration units. The AHF has significant relationships with cities. Moreover, the AHF is inversely proportional to the distances from cities [34]. Therefore, it is unreasonable that there is no change in AHF in certain areas.

Figure 5. Flanner's data of AHF, our data and spatial difference of AHF between Flanner and our data in $2005(2.5 \times 2.5 \mathrm{~min})$.
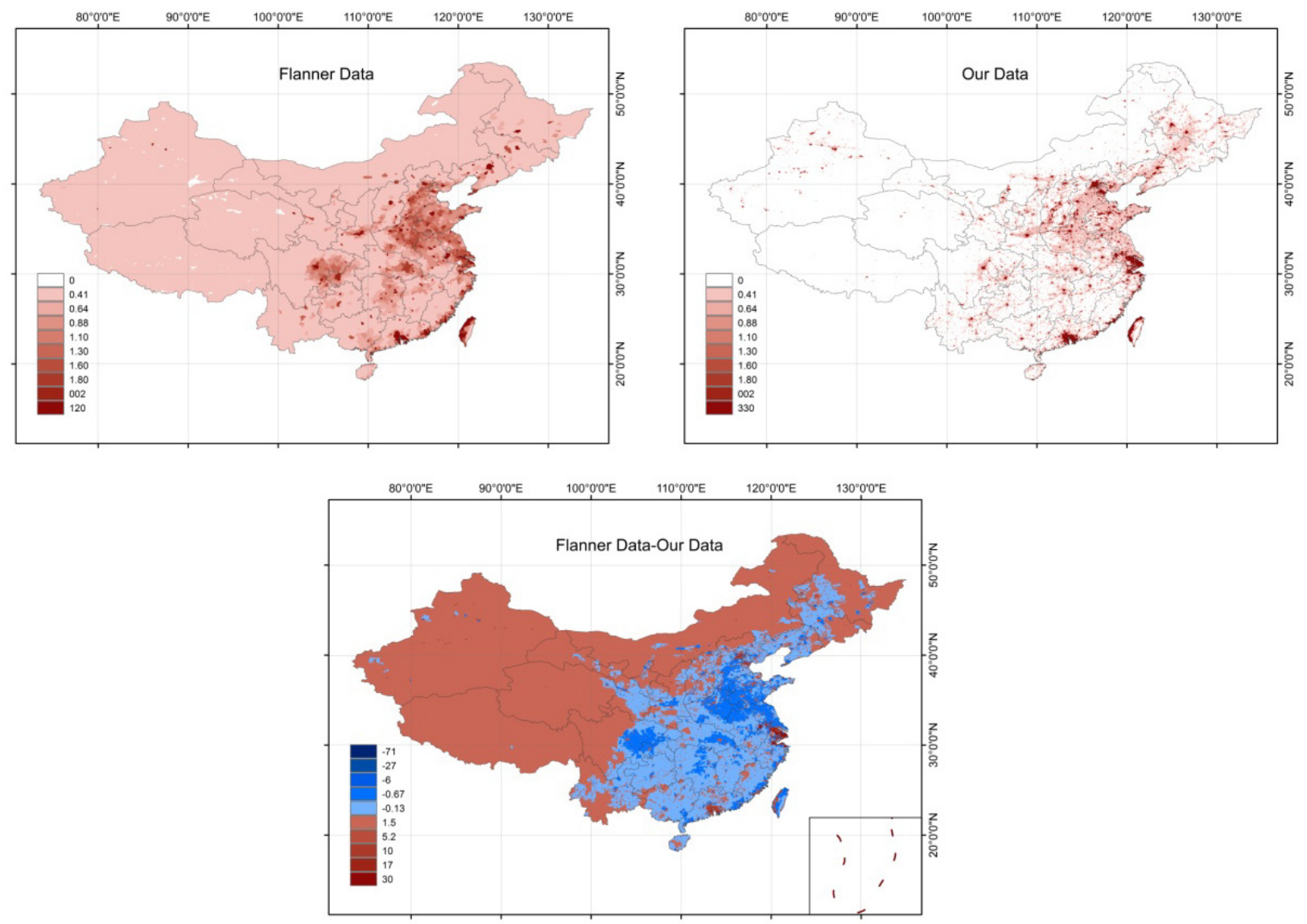

\subsubsection{Comparison of Province-Level AHF Data}

Annual average province-level AHF from Chen et al. were estimated using the energy consumption per province and corresponding areas [18]. Figure 6 shows that there is good consistency between these data; the slope of the curve is 1.6 and correlation coefficient is 0.945 . However, there are some deviations, e.g., the maximum AHF difference in Shanxi Province is $0.65 \mathrm{Wm}^{-2}$ and the minimum discrepancy in Xinjiang Province is $0.03 \mathrm{Wm}^{-2}$. Human metabolism was considered in estimating the annual average province-level AHF, which is a relatively small contribution in our data. Although the DMSP-OLS data have a strong linear relationship with energy consumption, the estimated 
non-renewable resources from a linear model for DMSP-OLS and energy consumption are not equivalent to the actual energy consumptions due to statistical errors, which will produce deviations in some provinces.

Figure 6. Comparison on AHF between chen's data and data based on DMSP-OLS.

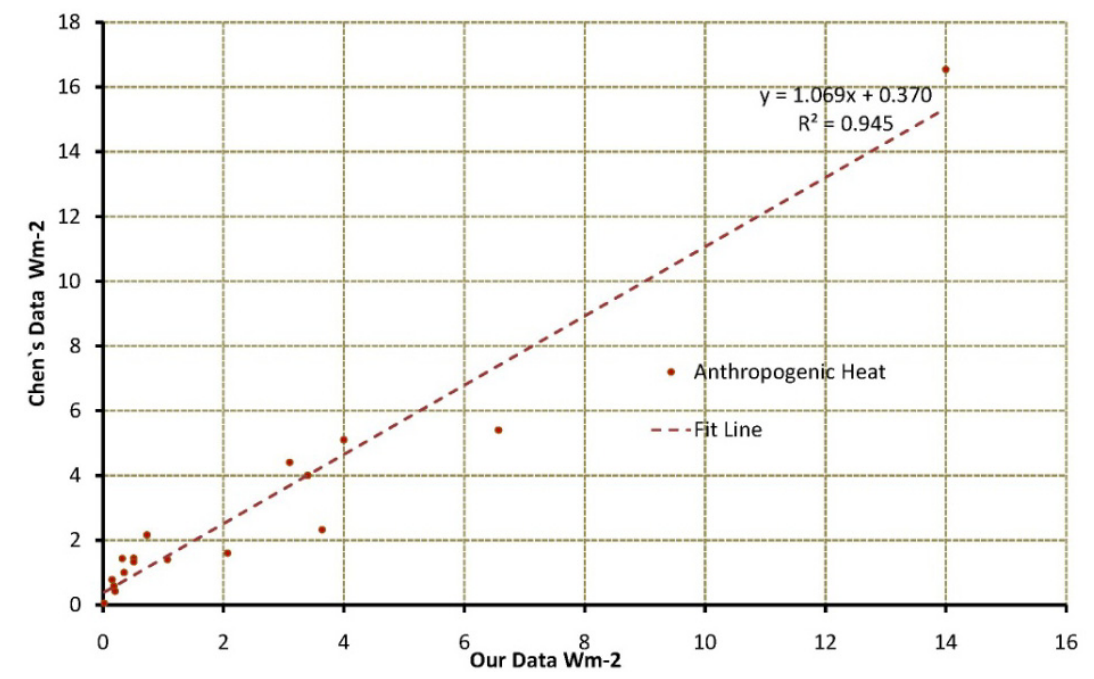

\subsubsection{Comparison of Single-City AHF Data}

The daily AHF for individual cities were acquired to validate our data. Because we used annual average AHF or yearly total energy per pixel, the AHF data needed to be converted to daily AHF using the yearly and daily weight curves of Flanner [17,20]. AHF in Beijing was estimated using the bottom-up method in which vehicles, building density and industry were modeled to estimate AHF. AHF in other cities was estimated using the top-down approach. Table 1 shows that our data have substantial inconsistencies with the AHF for individual cities reported in other studies. The largest difference is $70.23 \mathrm{Wm}^{-2}$ in Beijing; The smallest difference is $25.9 \mathrm{Wm}^{-2}$ in Guangzhou [19]. Comparing Flanner's, Chen's and single-city AHF data, our AHF are larger than Flanner's and Chen's and smaller than the single-city AHF. Moreover, single-city AHF is more accurate as they consider detailed information for individual cities at smaller scales. Since it is difficult to be access city-level social and economic statistics and the expense in estimating AHF, exploiting bottom-up methods to estimate AHF across China is unrealistic.

Table 1. The differences of our data and results of other's AHF.

\begin{tabular}{cccccc}
\hline Regions & $\begin{array}{c}\text { Flanner } \\
\left(\mathbf{W m}^{-\mathbf{2}}\right)\end{array}$ & $\begin{array}{c}\text { Chen } \\
\left(\mathbf{W m}^{-\mathbf{2}}\right)\end{array}$ & $\begin{array}{c}\text { Our Data } \\
\left(\mathbf{W m}^{-\mathbf{2}}\right)\end{array}$ & $\begin{array}{c}\text { AHF of Single City } \\
\left(\mathbf{W m}^{-\mathbf{2}}\right)\end{array}$ & $\begin{array}{c}\text { Estimating Methods of } \\
\text { Single City }\end{array}$ \\
\hline Beijing & - & 5.81 & 24.67 & $94.9[19]$ & Heat Emission Inventory \\
Guangzhou & 7.99 & 12 & 15.1 & $41[9]$ & Energy Based \\
Hangzhou & - & 7.84 & 17.36 & $50[35]$ & Energy Based \\
Xiaoshan & - & 4.62 & 14.9 & $40[35]$ & Energy Based \\
\hline
\end{tabular}

The differences between single-city AHF and our data are primarily due to the rules used for allocating total urban energy consumption to individual cities, i.e., the amount of apportioned energy 
that was consumed in some large cities was smaller than the actual demands. The other reason for this finding is that the daily and yearly weight curves do not depend on climate zones in China. Moreover, inconsistency in the urban areas selected by different authors may result in deviations, especially because too small of an urban area extent leads to high AHF in the corresponding city.

\section{Discussions}

Although anthropogenic heat is only about $0.3 \%$ of the total energy transport to the extra-tropics by atmospheric and oceanic circulations, human heat could disrupt the normal atmospheric circulation pattern and bring significant influences on surface temperature at global scales [12]. Therefore, incorporating anthropogenic heat into climate models could improve the performance of simulations of surface climate warming [12,36]. Increased urban heat could possibly reduce concentration of precursor species (e.g., $\mathrm{NO}_{\mathrm{x}}$ and $\mathrm{CO}$ ), while increase concentration of surface ozone [36,37], and raise risks of morbidity and mortality [38].

Our analysis shows higher AHF than Flanner's for urban regions, but smaller than values of studies in specific cities. The applied methodology could be improved in future in several ways. Firstly, our method assumes that all energy is converted into waste heat, which is unreasonable; Secondly, we use only non-renewable energy and the percentage of renewable energy is increasing; Thirdly, we use primary energy statistics not the final energy consumption in each location, which will exclude the waste heat released in the production process; Lastly, threshold and saturation in the DMSP-OLS data may make it difficult to monitor anthropogenic activity in mega-cities [39].

\section{Conclusions}

We allocated annual fossil energy consumption to DMSP-OLS data from 1992 to 2010 in China using the following procedure: (1) divide total energy consumption into urban and rural components; (2) apply threshold (digital number $\geq 12$ ) to distinguish urban and rural regions based on the DMSP-OLS data; (3) allocate energy consumption of urban area into each city based on the relationship between the urban area and energy consumption records from several specific Chinese cities; and (4) calculate AHF based on DMSP-OLS data for urban and rural areas separately.

Our results show that AHF increased greatly in China from 1992 to 2010. The biggest changes occurred in the Beijing-Tianjin region, the Yangzi River delta and the Pearl River delta. During the latter half of the studied period, AHF across China increased due to booming economic development. Compared with other data, our results show reasonable performance with better spatial distribution and larger magnitude for large cities than that in Flanner data. This illustrates that the proxy of DMSP-OLS is better than population density for AHF studies as it represents economic activity.

\section{Acknowledgments}

Thanks for technical supports by Yibo Luan and Chen Yang. This study was supported by National Basic Research Development Program of China (Grant No. 2010CB428502) and the General Project of the National Natural Science Foundation of China (Grant No. 41271542). 


\section{Author Contributions}

Xuefeng Cui had the original idea for the study and, with all co-authors carried out the design. Bing Chen contributed to the result analysis and Wangming Yang carried out the calculation and drafted the manuscript, which was revised by all authors. All authors read and approved the final manuscript.

\section{Conflicts of Interest}

The authors declare no conflict of interest.

\section{References}

1. American Meteorological Society. Available online: http://www.ametsoc.org/amsedu/ (accessed on 9 April 2014).

2. Smith, C.; Sarah, L.; Geoff, L. Estimating spatial and temporal patterns of urban anthropogenic heat fluxes for UK cities: The case of Manchester. Theor. Appl. Climatol. 2009, 98, 19-35.

3. Sailor, D.J. A review of methods for estimating anthropogenic heat and moisture emissions in the urban environment. Int. J. Climatol. 2011, 31, 189-199.

4. Sivak, M. Air conditioning versus heating: Climate control is more energy demanding in Minneapolis than in Miami. Environ. Res. Lett. 2013, 8, doi:10.1088/1748-9326/8/1/014050.

5. IPCC Special Report on Renewable Energy Sources and Climate Change Mitigation. Available online: http://www.ipcc.ch/pdf/presentations/Rio20/Rio20_puc_aivanova.pdf (accessed on 9 April 2014).

6. Quah, A.K.L.; Roth, M. Diurnal and weekly variation of anthropogenic heat emissions in a tropical city, Singapore. Atmos. Environ. 2012, 46, 92-103.

7. Ichinose, T.; Shimodozono, K.; Hanaki, K. Impact of anthropogenic heat on urban climate in Tokyo. Atmos. Environ. 1999, 33, 3897-3909.

8. Hamilton, I.G.; Davies, M.; Steadman, P.; Stone, A.; Ridley, I.; Evan, S. The significance of the anthropogenic heat emissions of London's buildings: A comparison against captured shortwave solar radiation. Build. Environ. 2009, 44, 807-817.

9. Wang, Z.; Wang, X. Estimation and sensitivity test of anthropogenic heat flux in Guangzhou. J. Meteorol. Sci. 2011, 31, 422-430 (in Chinese).

10. Feng, J.-M.; Wang, Y.-L.; Ma, Z.-G.; Liu, Y.-H. Simulating the regional impacts of urbanization and anthropogenic heat release on climate across China. J. Clim. 2012, 25, 7187-7203.

11. Block, A. Impacts of anthropogenic heat on regional climate patterns. Geophys. Res. Lett. 2004, 31, L12211. doi:10.1029/2004GL019852.

12. Zhang, G.J.; Cai, M.; Hu, A. Energy consumption and the unexplained winter warming over northern Asia and North America. Nat. Clim. Chang. 2013, 27, 1-5.

13. Kato, S.; Yamaguchi, Y. Analysis of urban heat-island effect using ASTER and ETM+ data: Separation of anthropogenic heat discharge and natural heat radiation from sensible heat flux. Remote Sens. Environ. 2005, 99, 44-54. 
14. Zhou, Y.; Weng, Q.; Gurney, K.R.; Shuai, Y.; Hu, X. Estimation of the relationship between remotely sensed anthropogenic heat discharge and building energy use. ISPRS J. Photogramm. Remote Sens. 2012, 67, 65-72.

15. Zhang, Y.; Balzter, H.; Wu, X. Spatial-temporal patterns of urban anthropogenic heat discharge in fuzhou china obseved from sensible heat flux using landsat TM/ETM+ data. Int. J. Remote Sens. 2013, 34, 1459-1477.

16. Kotthaus, S.; Grimmond, C.S.B. Identification of Micro-scale anthropogenic $\mathrm{CO}_{2}$, heat and moisture sources-Processing eddy covariance fluxes for a dense urban environment. Atmos. Environ. 2012, 57, 301-316.

17. Sailor, D.J.; Lu, L. A top-down methodology for developing diurnal and seasonal anthropogenic heating profiles for urban areas. Atmos. Environ. 2004, 38, 2737-2748.

18. Chen, B.; Shi, G.Y.; Dai, T.; Shen, Y.; Wang, B.; Yang, S.; Zhao, J. Climate forcing due to anthropogenic heat release over China. Clim. Environ. Res. 2011, 16, 717-722 (in Chinese).

19. Tong, H.; Liu, H.; Sang, J.; Hu, F. The impact of urban anthropogenic heat on Beijing heat environment. Clim. Environ. Res. 2004, 9, 411-421 (in Chinese).

20. Flanner, M.G. Integrating anthropogenic heat flux with global climate models. Geophys. Res. Lett. 2009, 36, doi:10.1029/2008g1036465.

21. Jing, L.; Zhang, L. Analysis on spatial distribution characteristics of urban energy consumption among capital cities in China. Resour. Sci. 2009, 31, 2086-2092 (in Chinese).

22. Chen, B.; Shi, G.; Wang, B.; Zhao, J.; Tan, S. Estimation of the anthropogenic heat release distribution in China from 1992 to 2009. Acta Meteorol. Sin. 2012, 26, 507-515.

23. Elvidge, C.D.; Baugh, K.E.; Kihn, E.A.; Korehl, H.E.; Davis, E.R. Mapping city lights with nighttime data from the DMSP Operational Linescan System. Photogramm. Eng. Remote Sens. 1997, 63, 727-734.

24. Milesi, C.; Elvidge, C.D.; Nemani, R.R.; Running, S.T. Assessing the impact of urban land development on net primary productivity in the southeastern United States. Remote Sens. Environ. 2003, 86, 401-410.

25. Wu, J.; Wang, Z.; Li, W.; Peng, J. Exploring factors affecting the relationship between light consumption and GDP based on DMSP/OLS nighttime satellite imagery. Remote Sens. Environ. 2013, 134, 111-119.

26. Version 4 DMSP-OLS Nighttime Lights Time Series. Available online: http:/ngdc.noaa. gov/eog/dmsp/downloadV4composites.html\#AVS (accessed on 9 April 2014).

27. Ziskin, D.; Baugh, K.; Hsu, C.-F.; Elvidge, C.D. Methods used for the 2006 radiance lights. In Proceedings of the 30th Asia-Pacific Advanced Network Meeting, Hanoi, Vietnam, 9-13 August 2010; pp. 131-142.

28. EIA, U.S. Energy Information Administration. International Energy Statistics. Available online: http://www.eia.gov/cfapps/ipdbproject/IEDIndex3.cfm?tid=44\&pid=44\&aid=2. (accessed on 9 April 2014).

29. CNKI, China National Knowledge Infrastructure .Available onlime: http://tongji.cnki.net/ kns55/brief/ (accessed on 9 April 2014).

30. National Bureau of Statistics of China. Available online: http://data.stats.gov.cn/index;jsessionid= D267DEE863EEF57B9BEE0A60CEC85954 (accessed on 9 April 2014). 
31. World Energy Outlook. Available online: http://www.worldenergyoutlook.org/ (accessed on 9 April 2014).

32. Offerle, B.; Grimmond, C.S.B.; Fortuniak, K. Heat storage and anthropogenic heat flux in relation to the energy balance of a central European city centre. Int. J. Climatol. 2005, 25, 1405-1419,

33. Allen, L.; Lindberg, F.; Grimmond, C.S.B. Global to city scale urban anthropogenic heat flux: Model and variability. Int. J. Climatol. 2011, 31, 1990-2005.

34. United States Environmental Protection Agency. Urban Heat Island Basics. In Reducing Urban Heat Islands: Compendium of Strategies; United States Environmental Protection Agency: New York, NY, USA, 2010.

35. Chen, Y.; Jiang, W.M.; Zhang, N.; He, X.F.; Zhou, R.W. Numerical simulation of the anthropogenic heat effect on urban boundary layer structure. Theor. Appl. Climatol. 2008, 97, 123-134.

36. Yu, M.; Carmichael, G.R.; Zhu, T.; Cheng, Y. Sensitivity of predicted pollutant levels to anthropogenic heat emissions in Beijing. Atmos. Environ. 2014, 89, 169-178.

37. Ryu, Y.-H.; Baik, J.-J.; Lee, S.-H. Effects of anthropogenic heat on ozone air quality in a megacity. Atmos. Environ. 2013, 80, 20-30.

38. Peter, A.; Stott, D.A.S.; Allen, M.R. Human contribution to the European heatwave of 2003. Nature 2004, 432, 610-614.

39. Ma, T.; Zhou, C.; Pei, T.; Haynie, S.; Fan, J. Quantitative estimation of urbanization dynamics using time series of DMSP/OLS nighttime light data: A comparative case study from China's cities. Remote Sens. Environ. 2012, 124, 99-107.

(C) 2014 by the authors; licensee MDPI, Basel, Switzerland. This article is an open access article distributed under the terms and conditions of the Creative Commons Attribution license (http://creativecommons.org/licenses/by/3.0/). 